\title{
Viscosidade como fator frenador de rotações II: estudos com carboximetilcelulose
}

\author{
Viscoelastic substances as a breaking factor of ocular rotations II: studies \\ with carboxymethylcellulose
}

André Auǵusto Homsi Jorge ${ }^{1}$

Harley Edison Amaral Bicas ${ }^{2}$

\section{RESUMO}

Objetivo: Determinar se forças de atrito viscoso podem, sob o ponto de vista quantitativo, agir como possíveis promotoras de estabilização ocular com manutenção dos movimentos rotacionais, dando noção dos valores necessários para a aplicabilidade no sistema ocular. Métodos: Um modelo mecânico foi elaborado para a medida de forças necessárias para vencer o atrito de uma esfera de alumínio parcialmente mergulhada em um líquido viscoso. Foram testadas soluções de carboximetilcelulose de $1 \%$ a $6 \%$ (com variação de $0,5 \%$ ). Outra variável foi a área de contato entre a esfera e o líquido viscoso. Resultados: A força encontrada, após correções e descontos apropriados, foi significativa (acima de 5 gf) nas soluções de carboximetilcelulose a partir de 3,5\% na maior área de contato $\left(587,8 \mathrm{~mm}^{2}\right)$, nas soluções de carboximetilcelulose a partir de $4,5 \%$ na área intermediária $\left(335,9 \mathrm{~mm}^{2}\right)$, nas soluções de carboximetilcelulose a 5,5\% e 6,0\% na menor área $\left(167,9 \mathrm{~mm}^{2}\right)$. Conclusão: Alguns dos líquidos viscosos testados aparentemente são capazes de obter força de atrito suficiente para a estabilização ocular, com destaque para as soluções de carboximetilcelulose a 5,5\% e 6,0\% que obtiveram bons resultados na menor área de contato.

Descritores: Músculos oculomotores; Movimentos oculares; Nistagmo fisiológico; Estrabismo; Viscosidade; Carboximetilcelulose; Rotação ocular

\section{INTRODUÇÃO}

Os desequilíbrios oculomotores podem ser classificados em estáticos e dinâmicos ${ }^{(1)}$. Exemplificam desequilíbrios estáticos os estrabismos, nos quais há uma alteração de posição relativa entre os eixos visuais a cada posição do objeto de fixação, apesar de serem possíveis rotações satisfatórias. Os desequilíbrios dinâmicos ocorrem quando há movimentos oculares incoordenados, ou coordenados mas indesejados, como em certas formas de nistagmos em que, ao contrário dos estrabismos, há um bom relacionamento direcional dos eixos visuais, porém com instabilidade da fixação ocular. Os nistagmos estão sempre relacionados à diminuição do poder visual discriminativo, além de prejudicarem, sensivelmente, a estética da pessoa, levando-a a constrangimentos sociais. Em certos casos, o nistagmo é decorrente de alterações estruturais que levam a uma baixa acuidade visual (como, por exemplo, uma placa cicatricial macular de coriorretinite) sendo, assim, conseqüência e não causa da baixa visão.

$\mathrm{O}$ tratamento dos nistagmos esbarra em muitos problemas, sendo poucos os tipos passíveis de intervenção. O mais favorável é aquele que apresenta "posição de bloqueio", situação posicional dos olhos na qual a 
instabilidade deixa de ocorrer ou diminui consideravelmente. Os resultados cirúrgicos são relativamente bons nesses tipos de nistagmo, porém com certas limitações. A primeira delas relaciona-se à magnitude das correções. Como o que se pretende é transferir o estado de bloqueio para a posição primária do olhar, e os ângulos das respectivas posições viciosas adotadas pela cabeça para garantir a estabilização ocular são habitualmente grandes (da ordem de $30^{\circ}$ a $40^{\circ}$, ou seja, 60 a 80 dioptrias prismáticas), freqüentemente ocorrerá dificuldade em atingir tal grau de correção, a não ser com prejuízo significativo das rotações oculares, ainda que em um único sentido. Outra limitação do tratamento cirúrgico é a possível assimetria da correção, pois corrigir uma "esotropia" de um olho e "exotropia" do outro, de igual magnitude (como se deve considerar), requer intervenções nem sempre simétricas, com resultados, portanto, também assimétricos. Dessa forma, poderá ocorrer um estado de desvio compensado (heteroforia) eventualmente causadora de sintomas, ou mesmo um desvio descompensado (heterotropia). Outro aspecto limitante no tratamento cirúrgico dos nistagmos diz respeito à instabilidade espacial, pois eles continuam a se manifestar com as mesmas características na posição oposta à de bloqueio e, geralmente, invertem-se na posição em que inicialmente estavam neutralizados. Por fim, também são descritos casos de instabilidade temporal com recidivas, ainda que parciais ${ }^{(1)}$.

Sendo a terapêutica cirúrgica atual (por meio de recuos, ressecções, transposições, etc.) insuficiente para a obtenção plena de bons resultados, as investigações de ponta nesta área visam à introdução de novas forças no sistema oculomotor. Forças de campo magnético poderiam dificultar ou impedir movimentos indesejados, como os dos nistagmos. Esses estudos são promissores, mas apresentam dificuldades. Bicas refere que a operacionalidade de um sistema de ímãs colocados em cada um dos olhos apresenta várias restrições: dificuldade de obtenção de ímãs de tamanhos reduzidos, que possibilitem sua aplicação dentro das órbitas, mas com forças magnéticas suficientemente intensas; as distâncias entre elementos do circuito magnético são relativamente grandes; dificuldade de controle das influências recíprocas exercida pelos campos magnéticos, resultando em tendência ao equilíbrio posicional diferente do desejado; presença inevitável de forças de translação grandes, aumentando o atrito e dificultando as próprias rotações a serem geradas; possibilidade de efeitos prejudiciais no cristalino e retina, causados por estes campos magnéticos $^{(2)}$. Além das restrições citadas pelo autor chama a atenção o fato de que um sistema oculomotor equilibrado por forças magnéticas demandaria um ajustamento binocular dinâmico possivelmente difícil.

Diante da idéia de se introduzirem novas forças no sistema oculomotor e de suas restrições, foi proposto em recente estudo o uso de forças viscoelásticas como alternativa para a estabilização do equilíbrio ocular, levando-se em consideração que a correção de qualquer desequilíbrio oculomotor deveria atender a certas exigências ${ }^{(3)}$. Num estrabismo tal correção deverá levar a um paralelismo dos eixos visuais em todas as direções, sem, entretanto, comprometer as rotações que deverão se manter conjugadas ${ }^{(1)}$. Considerando-se as forças necessárias para obtenção de rotações normais como $\mathrm{F}_{\mathrm{n}}$, as forças dos fatores de instabilidade (nistagmos, por exemplo) como $\mathrm{F}_{\mathrm{i}}$, e as forças envolvidas no sistema de correção de tais instabilidades como $\mathrm{F}$, tem-se, idealmente, a condição de $\mathrm{F}_{\mathrm{i}}<\mathrm{F}<\mathrm{F}_{\mathrm{n}}$, ou seja, $\mathrm{F}$ deverá ser maior que $\mathrm{F}_{\mathrm{i}}$, o suficiente para anulá-la, e menor que $\mathrm{F}_{\mathrm{n}}, \mathrm{o}$ suficiente para permitir a ação desta. Tal condição obviamente não poderá ser obtida por meio de suturas de contenção, pois, se pouco resistentes, neutralizariam, num primeiro momento, as forças de instabilidade (bloqueariam o nistagmo, por exemplo), mas seriam rompidas à primeira necessidade de uma rotação maior; e, se muito resistentes, impediriam qualquer movimento, fosse ele indesejável (nistagmo) ou desejável (rotações). Entretanto, há condições como as de forças de campo magnético e forças viscoelásticas, que poderiam propiciar um bloqueio das oscilações indesejadas, podendo ser vencido por forças mais intensas, relacionadas às rotações oculares.

Considerando-se as características do nistagmo, o qual apresenta fases lentas com velocidades semelhantes à de movimentos persecutórios e amplitudes em torno de $5^{\circ}$ a $10^{\circ}$, pode-se supor que as forças relacionadas a esses movimentos não sejam maiores que $10 \mathrm{gf}$, sendo provável que forças dessa grandeza, ou até menores sejam suficientes para bloqueálas ${ }^{(1)}$. Por outro lado, sabe-se que as forças ativas (de ação muscular) de um músculo atuando como agonista de um movimento sacádico são da ordem de 75 gf (rotação centrípeta) a 100 gf (rotação centrífuga) para rotações de $30^{\circ}$ e de 50 gf (rotação centrípeta) a 65 gf (rotação centrífuga) para rotações de $15^{\mathbf{o}(4)}$. Essas são as forças medidas no teste clássico de "forças geradas" descrito por Scott et al. em 1972 ${ }^{(5)}$. Assim, com forças viscoelásticas entre 5 e $10 \mathrm{gf}$, acredita-se ser possível, ao menos teoricamente, o bloqueio da maioria dos nistagmos com manutenção das rotações oculares (relacionadas a forças de maior magnitude).

Em um estudo preliminar com forças viscoelásticas foram utilizadas soluções de metilcelulose nas concentrações de 1 a $6 \%$ (variando de $0,5 \%$ ) e duas soluções viscoelásticas (Viscoat $^{\circledR} \mathrm{e}$ Provisc ${ }^{\circledR}$ ) porém os resultados obtidos sugeriram ser tais soluções possivelmente insuficientes para bloquear nistagmos ${ }^{(3)}$.

O presente estudo teve o objetivo de determinar, em um modelo mecânico, o efeito frenador de rotações de uma esfera, produzido por forças viscoelásticas de soluções de carboximetilcelulose em diferentes concentrações e em variadas áreas de contato, para estimativas quantitativas de suas viabilidades de aplicação "in vivo". Comparações com resultados obtidos em estudo preliminar serão também feitas.

\section{MÉTODOS}

\section{I) Modelo mecânico}

Para o presente estudo, foi concebido, junto ao Departamento de Física da Escola de Engenharia de São Carlos - 
U.S.P., um modelo mecânico (Figuras 1 e 2) que permitiu a medida de forças necessárias para vencer um atrito viscoso. Como se trabalhou com forças de pequena grandeza (da ordem de alguns gramas), necessitou-se de um sistema que apresentasse o mínimo atrito interno entre seus componentes, para que este não influenciasse, ou o fizesse de maneira pouco significativa, na determinação dos valores buscados. Para tal, o aparato mecânico foi acoplado a um sistema de mancal aerostático. Um mancal é constituído, basicamente, de duas partes: o munhão, que é a parte interna, cilíndrica, usualmente com movimento de rotação ou oscilação, e o mancal propriamente dito ou superfície de apoio, que pode ser estacionário ou móvel ${ }^{(6)}$. Entre as duas partes, existe uma folga que é ocupada pelo lubrificante do mancal. Segundo Purquério são três os tipos principais de mancais lubrificados a ar: aerodinâmicos, película comprimida e aerostáticos (pressurizados externamente $)^{(7)}$. Nesse último tipo, que foi o utilizado neste estudo, um sistema externo de ar pressurizado alimenta o mancal, formando uma fina e rígida película de ar entre seus componentes, minimizando seu atrito interno.

O modelo mecânico elaborado foi composto por um eixo metálico $(\mathrm{X})$ horizontal rotador, sendo que, em uma de suas extremidades, havia uma esfera de alumínio (E), de $26,73 \mathrm{~mm}$ de diâmetro, que apresentava movimento de rotação coincidente com o do referido eixo. A porção contralateral à esfera foi

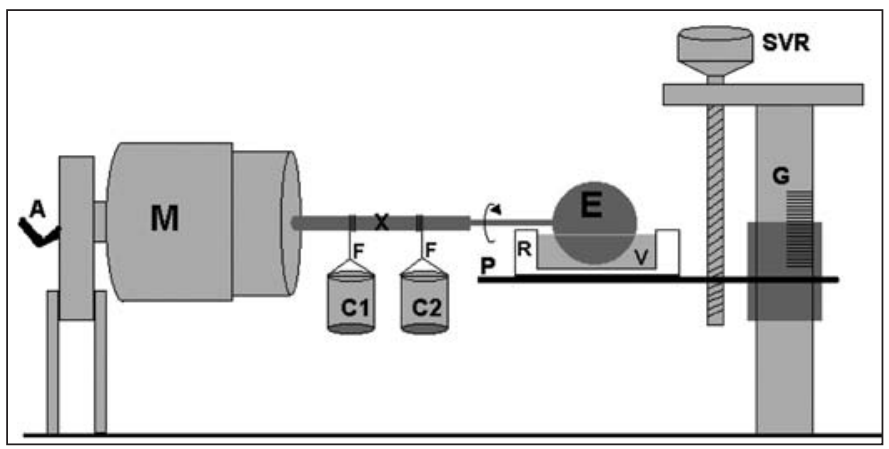

Figura 1 - Esquema ilustrativo do modelo mecânico utilizado

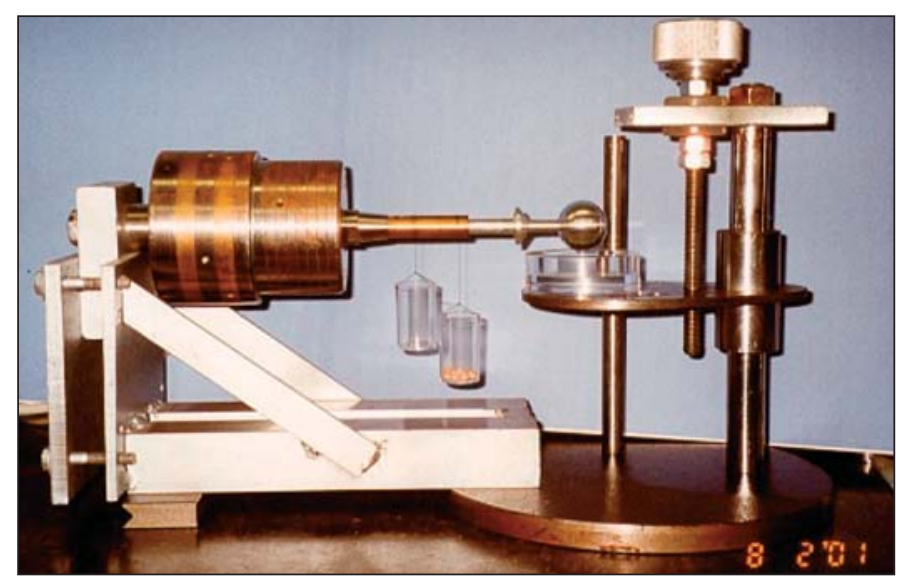

Figura 2 - Modelo mecânico utilizado no estudo acoplada a um sistema de mancal aerostático (M) de modo que o eixo ficasse envolvido por uma camada de ar pressurizado, controlado por manômetro, alimentado por um sistema externo (A), podendo, dessa forma, girar sem contato físico com qualquer outra estrutura do aparelho. Pendurados à porção intermediária do eixo, por meio de um fio de seda 4-0 não distensível (F), encontravam-se dois pequenos recipientes cilíndricos de acrílico (C1 e C2) que, por serem idênticos, ficavam suspensos no ar, em equilíbrio, como dois pratos de uma balança. A esfera de alumínio era, então, parcialmente mergulhada em um recipiente relativamente raso, de acrílico (R), contendo a substância viscosa (V) a ser estudada. O volume de substância viscosa no recipiente foi constante para todas as medidas $(11 \mathrm{ml})$. A porção da esfera mergulhada no gel manteve-se constante durante um mesmo experimento, mas variou de um experimento para outro. Um sistema vertical de rosca (SVR) graduado foi acoplado à plataforma $(\mathrm{P})$ permitindo, assim, seu movimento no sentido vertical. Sobre essa plataforma, era colocado o recipiente com a substância viscosa e, desse modo, pôde-se controlar a quantidade de gel que entraria em contato com a esfera que permaneceu sempre fixa nos sentidos vertical e horizontal. Assim, o recipiente com o líquido viscoso era colocado sobre a plataforma, bem abaixo da esfera, e esse conjunto $(\mathrm{R}+\mathrm{P})$ era elevado em direção à esfera até que esta ficasse parcialmente imersa, sendo a quantidade mergulhada controlada pela graduação (G) (em milímetros) do sistema vertical de rosca. Portanto, dessa maneira, havia um fator frenador para o movimento rotacional do conjunto eixo/esfera, que era o líquido viscoso, e dever-se-ia medir a força necessária para vencer esse fator e, consequientemente, promover a rotação.

Essa força foi determinada do seguinte modo: em um dos recipientes acrílicos pendurados ao eixo ( $\mathrm{C} 1$, por exemplo), iam-se colocando, com uma pinça, pequenas peças de plástico ou metal, até se chegar a um peso no recipiente capaz de promover a rotação do eixo (por força tangencial gravitacional) e, por consegüinte, da esfera. O conteúdo colocado no recipiente cilíndrico era, então, pesado em uma balança de precisão (centésimos de grama), obtendo-se o valor da força (em gramas) necessária para vencer o fator frenador viscoso daquela determinada substância. As variáveis foram a viscosidade e a área de contato entre o gel e a esfera.

\section{II) Produtos e preparados viscoelásticos}

Em relação à viscosidade foram, num estudo $\operatorname{preliminar}^{(3)}$, analisadas soluções de metilcelulose em concentrações de $1 \% ; 1,5 \% ; 2,0 \% ; 2,5 \% ; 3,0 \% ; 3,5 \% ; 4,0 \% ; 4,5 \% ; 5,0 \% ; 5,5 \% \mathrm{e}$ $6,0 \%$, além de dois viscoelásticos $\left(\right.$ Viscoat $^{\circledR}$ e Provisc $^{\circledR}$ ). Neste estudo analisamos soluções de carboximetilcelulose em concentrações de $1 \% ; 1,5 \% ; 2,0 \% ; 2,5 \% ; 3,0 \% ; 3,5 \% ; 4,0 \% ; 4,5 \%$; $5,0 \% ; 5,5 \%$ e $6,0 \%$. As soluções de metilcelulose e carboximetilcelulose foram preparadas e fornecidas pela Farmácia Ophthalmos e os outros dois produtos foram fornecidos pelo fabricante (Alcon Laboratórios). 


\section{III) Áreas de contato}

Foram estudadas três diferentes áreas de contato para cada substância, conforme ilustra a figura 3. A primeira área (denominada ÁREA 1) possuía 587,6 mm² a segunda (ÁREA 2) possuía $335,8 \mathrm{~mm}^{2}$, e a terceira (ÁREA 3) possuía $167,9 \mathrm{~mm}^{2}$.

As áreas foram calculadas a partir da fórmula: $S=2 \pi R h$, sendo $\mathrm{S}$ a área a ser determinada, $\mathrm{R}$ o raio da esfera, $\mathrm{h}$ a altura da esfera mergulhada no gel. Sendo R constante (13,36 mm), o que determinou a variação da área foi h (que pôde ser modificada graças ao sistema vertical de rosca). Dessa forma, a altura h foi de $7 \mathrm{~mm}$ para a ÁREA 1, de $4 \mathrm{~mm}$ para a ÁREA $2 \mathrm{e}$ de 2 mm para a ÁREA 3.

Sabe-se que a temperatura interfere na viscosidade dos líquidos de maneira inversamente proporcional. Em razão dessa influência, e por vislumbrar aplicabilidade "in vivo" deste estudo, teve-se o cuidado de executar as medidas a uma temperatura entre 37,5 e $38^{\circ} \mathrm{C}$. Para isso, mantiveram-se as soluções a serem estudadas dentro de seringas que eram colocadas em banho-maria, controlado por termômetro.

Inicialmente, quantificou-se o atrito interno do sistema que, apesar de minimizado pelo mancal, não foi nulo. Para tal quantificação, fez-se uma série de dez medidas (colocando as pequenas peças em um dos recipientes cilíndricos), estando a esfera suspensa no ar. A média foi calculada para posterior desconto nas medidas subseqüentes.

Após a quantificação do atrito interno, passou-se a estudar a ÁREA 1, fazendo-se duas séries de cinco medidas para cada substância, totalizando-se dez medidas. Entre as duas séries, o gel era recolocado em banho-maria para que a temperatura não se alterasse significativamente. Após as dez medidas, a esfera e o recipiente ( $R$ ) eram lavados e secados e, assim, outra substância (previamente mantida em banho-maria) passava a ser avaliada. A mesma seqüência foi repetida para as outras duas áreas estudadas.

Finalmente, como a força medida foi aplicada tangencialmente sobre o eixo, e não sobre a esfera, sendo o diâmetro (e, conseqüentemente, o momento da força) diferente para essas duas estruturas, foi necessária a correção dos valores encontrados. O diâmetro do eixo $\left(\mathrm{d}_{\mathrm{x}}\right)$, no local de aplicação da força, era de $12,3 \mathrm{~mm}$, enquanto que o diâmetro da esfera $\left(\mathrm{d}_{\mathrm{e}}\right)$, conforme já

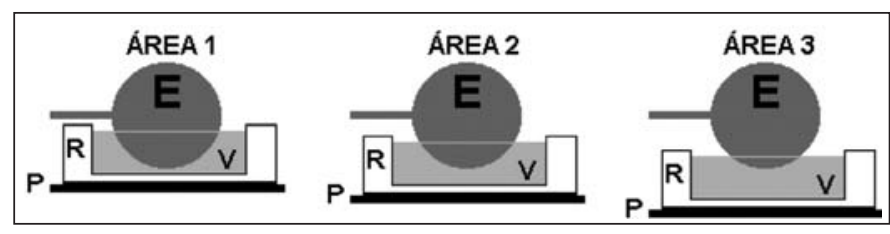

Figura 3 - Esquema ilustrando as diferentes áreas de contato dito, era de 26,73 mm. Nesses casos, a força é inversamente proporcional ao diâmetro da estrutura onde é aplicada. Portanto, considerando-se $\mathrm{F}_{\mathrm{x}}$ a força aplicada ao eixo (conforme ocorreu no estudo) e $F_{e}$ a força que se encontraria se a mesma fosse aplicada tangencialmente à esfera, concluir-se-à que:

$$
\begin{aligned}
\mathrm{F}_{\mathrm{e}} & =\mathrm{F}_{\mathrm{x}} \mathrm{d}_{\mathrm{x}} / \mathrm{d}_{\mathrm{e}} \\
\mathrm{F}_{\mathrm{e}} & =0,46 \mathrm{~F}_{\mathrm{x}}
\end{aligned}
$$

Desse modo, os resultados que serão apresentados foram corrigidos pelo fator acima demonstrado.

Foi utilizado, na análise estatística da variável força, o método denominado "Análise de Variância Multifatorial" e, rejeitando-se $\mathrm{H}_{0}$, isto é, havendo diferença estatística significativa, foi utilizado o teste post-hoc de Tukey.

\section{RESULTADOS}

As medidas obtidas na avaliação do atrito interno do sistema estão mostradas na tabela 1 . As medidas obtidas no estudo das ÁREAS 1, 2 e 3 estão relacionadas nas tabelas 2,3 e 4 , respectivamente.

O gráfico 1 relaciona os resultados obtidos no estudo da ÁREA 1 para as diferentes concentrações de metilcelulose e carboximetilcelulose.

O gráfico 2 relaciona os resultados obtidos no estudo da ÁREA 2 para as diferentes concentrações de metilcelulose e carboximetilcelulose.

O gráfico 3 relaciona os resultados obtidos no estudo da ÁREA 3 para as diferentes concentrações de metilcelulose e carboximetilcelulose.

O gráfico 4 compara as seis curvas obtidas no estudo das diferentes áreas.

O gráfico 5 relaciona a força obtida com as três diferentes áreas estudadas. São representadas as curvas das soluções de metilcelulose a $1 \%, 2 \%, 3 \%, 4 \%, 5 \%$ e $6 \%$, além das curvas de Viscoat ${ }^{\circledR}$ e Provisc $^{\circledR}$.

O gráfico 6 relaciona a força obtida com as três diferentes áreas estudadas. São representadas as curvas das soluções de carboximetilcelulose a $1 \%, 2 \%, 3 \%, 4 \%, 5 \%$ e $6 \%$.

\section{DISCUSSÃO}

Substâncias viscosas são amplamente utilizadas em Oftalmologia, tanto em contato com a córnea (exame de gonioscopia, aplicação de YAG laser) como em uso intra-ocular (especialmente na cirurgia de catarata). Os produtos utilizados neste estudo, fazem parte desse arsenal já tendo, assim, compro-

\begin{tabular}{|c|c|c|c|c|c|c|c|c|c|c|c|c|}
\hline & $\begin{array}{c}\text { Medida } \\
1\end{array}$ & $\begin{array}{c}\text { Medida } \\
2\end{array}$ & $\begin{array}{c}\text { Medida } \\
3\end{array}$ & $\begin{array}{c}\text { Medida } \\
4\end{array}$ & $\begin{array}{c}\text { Medida } \\
5\end{array}$ & $\begin{array}{c}\text { Medida } \\
6\end{array}$ & $\begin{array}{c}\text { Medida } \\
7\end{array}$ & $\begin{array}{c}\text { Medida } \\
8\end{array}$ & $\begin{array}{c}\text { Medida } \\
9\end{array}$ & $\begin{array}{c}\text { Medida } \\
10\end{array}$ & Média & $\begin{array}{l}\text { Desvio } \\
\text { padrão }\end{array}$ \\
\hline $\begin{array}{l}\text { Força (em gf) para } \\
\text { vencer o atrito } \\
\text { interno do sistema }\end{array}$ & 0,17 & 0,16 & 0,21 & 0,19 & 0,20 & 0,26 & 0,20 & 0,30 & 0,26 & 0,25 & 0,22 & 0,0452 \\
\hline
\end{tabular}
vada a sua condição de inertes aos tecidos oculares. 


\begin{tabular}{|c|c|c|c|c|c|c|c|c|c|c|c|c|c|c|}
\hline Substância & $\underset{1}{\text { Medida }}$ & $\begin{array}{l}\text { Medida } \\
2\end{array}$ & $\begin{array}{c}\text { Medida } \\
3\end{array}$ & $\underset{4}{\text { Medida }}$ & $\begin{array}{l}\text { Medida } \\
5\end{array}$ & $\begin{array}{c}\text { Medida } \\
6\end{array}$ & $\begin{array}{c}\text { Medida } \\
7\end{array}$ & $\begin{array}{c}\text { Medida } \\
8\end{array}$ & $\begin{array}{c}\text { Medida } \\
9\end{array}$ & $\begin{array}{c}\text { Medida } \\
10\end{array}$ & Média & $\begin{array}{l}\text { Desvio } \\
\text { padrão }\end{array}$ & $\begin{array}{c}\text { Média-Atrito } \\
=F \mathbf{x}\end{array}$ & $\begin{array}{c}F e= \\
0,46 \mathrm{Fx}\end{array}$ \\
\hline M.C. $1,0 \%$ & 0,54 & 0,31 & 0,35 & 0,27 & 0,45 & 0,84 & 0,52 & 0,62 & 0,53 & 0,56 & 0,50 & 0,17 & 0,28 & 0,13 \\
\hline M.C. $1,5 \%$ & 0,73 & 0,44 & 0,56 & 0,35 & 0,38 & 0,85 & 0,74 & 0,74 & 0,73 & 0,49 & 0,60 & 0,18 & 0,38 & 0,17 \\
\hline M.C. $2,0 \%$ & 1,12 & 0,84 & 1,18 & 0,95 & 0,95 & 0,99 & 0,87 & 0,85 & 0,77 & 0,85 & 0,94 & 0,13 & 0,78 & 0,36 \\
\hline M.C. $2,5 \%$ & 2,39 & 2,34 & 2,29 & 2,44 & 2,37 & 1,57 & 1,48 & 1,42 & 1,52 & 1,51 & 1,93 & 0,46 & 1,71 & 0,79 \\
\hline M.C. $3,0 \%$ & 3,21 & 2,92 & 2,86 & 3,14 & 3,11 & 2,17 & 2,12 & 2,08 & 2,32 & 2,27 & 2,62 & 0,47 & 2,40 & 1,10 \\
\hline M.C. $3,5 \%$ & 4,01 & 3,72 & 4,08 & 4,14 & 4,34 & 3,36 & 3,07 & 3,25 & 3,50 & 3,48 & 3,69 & 0,43 & 3,47 & 1,60 \\
\hline M.C. $4,0 \%$ & 4,96 & 4,83 & 4,90 & 4,81 & 5,08 & 4,53 & 4,46 & 4,43 & 4,70 & 4,77 & 4,75 & 0,22 & 4,53 & 2,08 \\
\hline M.C. $4,5 \%$ & 7,49 & 7,76 & 6,73 & 7,49 & 7,45 & 6,74 & 6,74 & 6,73 & 6,92 & 7,09 & 7,11 & 0,40 & 6,89 & 3,17 \\
\hline M.C. $5,0 \%$ & 8,30 & 8,30 & 8,30 & 9,40 & 8,30 & 9,35 & 7,08 & 8,30 & 8,71 & 9,43 & 8,55 & 0,72 & 8,33 & 3,83 \\
\hline M.C. $5,5 \%$ & 15,91 & 13,86 & 13,90 & 13,46 & 13,28 & 12,75 & 12,63 & 12,50 & 13,66 & 13,86 & 13,58 & 0,98 & 13,36 & 6,14 \\
\hline M.C. $6,0 \%$ & 14,79 & 13,67 & 15,90 & 15,90 & 14,79 & 15,89 & 14,85 & 15,40 & 14,91 & 14,89 & 15,10 & 0,70 & 14,88 & 6,84 \\
\hline C.M.C. $1,0 \%$ & 1,07 & 0,68 & 0,77 & 0,75 & 0,73 & 0,75 & 0,85 & 0,72 & 0,82 & 0,80 & 0,79 & 0,11 & 0,57 & 0,26 \\
\hline C.M.C. 1,5\% & 1,45 & 1,60 & 1,49 & 1,48 & 1,42 & 1,52 & 1,57 & 1,43 & 1,49 & 1,48 & 1,49 & 0,06 & 1,27 & 0,58 \\
\hline C.M.C. $2,0 \%$ & 2,96 & 2,98 & 2,90 & 2,97 & 2,98 & 2,99 & 2,95 & 2,94 & 3,02 & 2,97 & 2,97 & 0,03 & 2,75 & 1,26 \\
\hline C.M.C. $2,5 \%$ & 4,48 & 4,49 & 4,68 & 4,49 & 4,68 & 5,10 & 5,05 & 5,02 & 4,83 & 4,85 & 4,77 & 0,24 & 4,55 & 2,09 \\
\hline C.M.C. $3,0 \%$ & 10,12 & 10,29 & 10,11 & 9,40 & 10,18 & 9,80 & 10,39 & 10,11 & 10,29 & 9,60 & 10,03 & 0,32 & 9,81 & 4,51 \\
\hline C.M.C. $3,5 \%$ & 13,15 & 12,95 & 11,67 & 11,66 & 12,09 & 11,68 & 10,55 & 12,27 & 12,68 & 13,24 & 12,19 & 0,84 & 11,97 & 5,51 \\
\hline C.M.C. $4,0 \%$ & 19,26 & 23,88 & 22,64 & 24,20 & 19,75 & 23,96 & 20,29 & 25,56 & 21,49 & 23,32 & 22,43 & 2,13 & 22,21 & 10,22 \\
\hline C.M.C. $4,5 \%$ & 27,29 & 26,05 & 27,74 & 24,98 & 27,07 & 25,41 & 25,73 & 25,54 & 25,72 & 27,55 & 26,31 & 1,00 & 26,09 & 11,99 \\
\hline C.M.C. $5,0 \%$ & 30,46 & 32,66 & 28,96 & 29,45 & 27,84 & 31,10 & 31,23 & 31,75 & 29,80 & 33,97 & 30,72 & 1,82 & 30,50 & 14,03 \\
\hline C.M.C. $5,5 \%$ & 36,20 & 38,62 & 35,22 & 34,03 & 36,72 & 39,06 & 34,41 & 37,45 & 32,06 & 37,87 & 36,16 & 2,23 & 35,94 & 16,53 \\
\hline C.M.C. $6,0 \%$ & 47,21 & 50,43 & 49,95 & 52,72 & 52,69 & 50,01 & 49,65 & 51,49 & 50,45 & 54,20 & 50,88 & 1,97 & 50,66 & 23,30 \\
\hline Viscoat & 1,19 & 1,21 & 1,22 & 1,23 & 1,14 & 1,15 & 1,13 & 1,13 & 1,17 & 1,18 & 1,17 & 0,04 & 0,95 & 0,44 \\
\hline ProVisc & 2,98 & 2,74 & 2,60 & 2,81 & 2,75 & 2,77 & 2,98 & 2,70 & 2,82 & 2,90 & 2,80 & 0,12 & 2,58 & 1,19 \\
\hline
\end{tabular}

\begin{tabular}{|c|c|c|c|c|c|c|c|c|c|c|c|c|c|c|}
\hline Substância & $\begin{array}{c}\text { Medida } \\
1\end{array}$ & $\begin{array}{l}\text { Medida } \\
\quad 2\end{array}$ & $\begin{array}{c}\text { Medida } \\
\quad 3\end{array}$ & $\begin{array}{c}\text { Medida } \\
\quad 4\end{array}$ & $\begin{array}{l}\text { Medida } \\
\quad 5\end{array}$ & $\begin{array}{c}\text { Medida } \\
\quad 6\end{array}$ & $\begin{array}{c}\text { Medida } \\
7\end{array}$ & $\begin{array}{c}\text { Medida } \\
\quad 8\end{array}$ & $\begin{array}{c}\text { Medida } \\
9\end{array}$ & $\begin{array}{c}\text { Medida } \\
10\end{array}$ & Média & $\begin{array}{l}\text { Desvio } \\
\text { padrão }\end{array}$ & $\begin{array}{c}\text { Média-Atrito } \\
=\mathbf{F x}\end{array}$ & $\begin{array}{c}F e= \\
0,46 \mathrm{Fx}\end{array}$ \\
\hline M.C. $1,0 \%$ & 0,57 & 0,66 & 0,36 & 0,38 & 0,29 & 0,51 & 0,44 & 0,46 & 0,40 & 0,44 & 0,45 & 0,11 & 0,23 & 0,10 \\
\hline M.C. $1,5 \%$ & 0,54 & 0,66 & 0,57 & 0,50 & 0,45 & 0,75 & 0,65 & 0,52 & 0,51 & 0,50 & 0,56 & 0,09 & 0,34 & 0,16 \\
\hline M.C. $2,0 \%$ & 0,74 & 0,84 & 0,88 & 0,82 & 0,75 & 0,93 & 0,83 & 0,78 & 0,80 & 0,79 & 0,81 & 0,06 & 0,59 & 0,27 \\
\hline M.C. $2,5 \%$ & 1,44 & 1,45 & 1,31 & 1,29 & 1,31 & 1,20 & 1,28 & 1,15 & 1,36 & 1,33 & 1,31 & 0,09 & 1,09 & 0,50 \\
\hline M.C. $3,0 \%$ & 1,82 & 1,84 & 1,81 & 1,72 & 1,98 & 1,67 & 1,78 & 1,85 & 1,83 & 1,77 & 1,81 & 0,08 & 1,59 & 0,73 \\
\hline M.C. $3,5 \%$ & 2,53 & 2,63 & 2,40 & 2,56 & 2,41 & 2,54 & 2,24 & 2,35 & 2,55 & 2,78 & 2,50 & 0,15 & 2,28 & 1,05 \\
\hline M.C. $4,0 \%$ & 3,30 & 3,13 & 3,25 & 3,34 & 3,34 & 3,31 & 3,12 & 3,11 & 3,18 & 3,17 & 3,22 & 0,09 & 3,00 & 1,38 \\
\hline M.C. $4,5 \%$ & 4,23 & 4,32 & 4,43 & 4,61 & 4,76 & 4,28 & 4,51 & 4,25 & 4,27 & 4,48 & 4,41 & 0,18 & 4,19 & 1,93 \\
\hline M.C. $5,0 \%$ & 5,34 & 5,35 & 4,77 & 5,60 & 5,61 & 5,36 & 5,39 & 5,05 & 5,23 & 5,26 & 5,29 & 0,25 & 5,07 & 2,33 \\
\hline M.C. $5,5 \%$ & 6,05 & 6,08 & 6,06 & 6,01 & 6,10 & 5,70 & 6,14 & 6,06 & 5,87 & 6,27 & 6,03 & 0,15 & 5,81 & 2,67 \\
\hline M.C. $6,0 \%$ & 6,72 & 6,95 & 6,94 & 7,39 & 7,26 & 7,26 & 7,30 & 6,90 & 6,78 & 7,09 & 7,05 & 0,23 & 6,83 & 3,14 \\
\hline C.M.C. $1,0 \%$ & 0,64 & 0,69 & 0,51 & 0,52 & 0,53 & 0,52 & 0,54 & 0,54 & 0,51 & 0,57 & 0,56 & 0,06 & 0,34 & 0,16 \\
\hline C.M.C. $1,5 \%$ & 1,40 & 1,47 & 1,48 & 1,29 & 1,41 & 1,58 & 1,40 & 1,50 & 1,47 & 1,39 & 1,44 & 0,08 & 1,22 & 0,56 \\
\hline C.M.C. $2,0 \%$ & 1,99 & 2,12 & 2,19 & 2,10 & 2,24 & 2,07 & 1,93 & 2,17 & 2,12 & 2,00 & 2,09 & 0,10 & 1,87 & 0,86 \\
\hline C.M.C. $2,5 \%$ & 2,86 & 3,05 & 3,05 & 3,31 & 2,78 & 3,05 & 3,21 & 3,51 & 3,82 & 3,05 & 3,17 & 0,31 & 2,95 & 1,36 \\
\hline C.M.C. $3,0 \%$ & 4,87 & 4,96 & 5,05 & 6,03 & 4,94 & 5,30 & 4,95 & 4,96 & 4,69 & 5,56 & 5,13 & 0,40 & 4,91 & 2,26 \\
\hline C.M.C. $3,5 \%$ & 6,43 & 5,90 & 5,93 & 6,06 & 5,80 & 5,47 & 4,95 & 5,47 & 5,31 & 6,08 & 5,74 & 0,44 & 5,52 & 2,54 \\
\hline C.M.C. $4,0 \%$ & 7,97 & 7,90 & 7,45 & 7,9 & 8,58 & 8,78 & 9,87 & 9,91 & 10,39 & 10,78 & 8,95 & 1,19 & 8,73 & 4,01 \\
\hline C.M.C. $4,5 \%$ & 13,65 & 12,84 & 13,48 & 13,34 & 13,76 & 14,46 & 13,14 & 14,46 & 14,77 & 13,34 & 13,72 & 0,64 & 13,50 & 6,21 \\
\hline C.M.C. $5,0 \%$ & 16,31 & 16,17 & 17,34 & 17,29 & 17,35 & 18,41 & 16,23 & 16,17 & 18,46 & 18,14 & 17,19 & 0,93 & 16,97 & 7,81 \\
\hline C.M.C. $5,5 \%$ & 20,87 & 23,20 & 21,98 & 23,20 & 19,74 & 21,08 & 22,83 & 23,33 & 21,98 & 20,96 & 21,92 & 1,23 & 21,70 & 9,98 \\
\hline C.M.C. $6,0 \%$ & 26,50 & 26,18 & 27,71 & 27,3 & 28,82 & 26,70 & 27,69 & 26,81 & 28,82 & 28,42 & 27,49 & 0,96 & 27,27 & 12,54 \\
\hline Viscoat & 1,08 & 1,14 & 0,97 & 0,98 & 0,91 & 0,88 & 0,92 & 0,87 & 1,01 & 0,87 & 0,96 & 0,09 & 0,74 & 0,34 \\
\hline ProVisc & 2,00 & 1,75 & 1,98 & 2,04 & 2,19 & 2,02 & 1,88 & 2,03 & 1,92 & 2,03 & 1,98 & 0,12 & 1,76 & 0,81 \\
\hline
\end{tabular}




\begin{tabular}{|c|c|c|c|c|c|c|c|c|c|c|c|c|c|c|}
\hline Substância & $\underset{1}{\text { Medida }}$ & $\begin{array}{l}\text { Medida } \\
2\end{array}$ & $\begin{array}{c}\text { Medida } \\
3\end{array}$ & $\begin{array}{c}\text { Medida } \\
4\end{array}$ & $\begin{array}{l}\text { Medida } \\
5\end{array}$ & $\begin{array}{c}\text { Medida } \\
6\end{array}$ & $\begin{array}{c}\text { Medida } \\
7\end{array}$ & $\begin{array}{c}\text { Medida } \\
8\end{array}$ & $\begin{array}{c}\text { Medida } \\
9\end{array}$ & $\begin{array}{c}\text { Medida } \\
10\end{array}$ & Média & $\begin{array}{l}\text { Desvio } \\
\text { padrão }\end{array}$ & $\begin{array}{c}\text { Média-Atrito } \\
=\mathrm{Fx}\end{array}$ & $\begin{array}{c}F e= \\
0,46 \text { Fx }\end{array}$ \\
\hline M.C. $1,0 \%$ & 0,59 & 0,42 & 0,27 & 0,39 & 0,37 & 0,45 & 0,36 & 0,35 & 0,37 & 0,44 & 0,40 & 0,08 & 0,18 & 0,08 \\
\hline M.C. $1,5 \%$ & 0,50 & 0,41 & 0,37 & 0,40 & 0,48 & 0,44 & 0,57 & 0,62 & 0,55 & 0,54 & 0,49 & 0,08 & 0,27 & 0,12 \\
\hline M.C. $2,0 \%$ & 0,82 & 0,70 & 0,81 & 0,69 & 0,88 & 0,84 & 0,72 & 0,70 & 0,70 & 0,78 & 0,76 & 0,07 & 0,54 & 0,25 \\
\hline M.C. $2,5 \%$ & 1,00 & 1,11 & 0,99 & 1,06 & 1,06 & 0,96 & 1,06 & 1,11 & 1,05 & 1,04 & 1,04 & 0,05 & 0,82 & 0,38 \\
\hline M.C. $3,0 \%$ & 1,44 & 1,46 & 1,42 & 1,47 & 1,37 & 1,41 & 1,62 & 1,47 & 1,60 & 1,50 & 1,48 & 0,08 & 1,26 & 0,58 \\
\hline M.C. $3,5 \%$ & 1,82 & 1,85 & 1,84 & 1,83 & 1,85 & 1,82 & 1,66 & 1,86 & 1,95 & 1,84 & 1,83 & 0,07 & 1,61 & 0,74 \\
\hline M.C. $4,0 \%$ & 2,71 & 2,58 & 2,75 & 2,82 & 2,78 & 2,81 & 2,68 & 2,77 & 2,81 & 2,58 & 2,73 & 0,09 & 2,51 & 1,15 \\
\hline M.C. $4,5 \%$ & 3,14 & 3,15 & 2,98 & 3,13 & 2,98 & 3,35 & 3,26 & 3,35 & 3,34 & 3,34 & 3,20 & 0,15 & 2,98 & 1,37 \\
\hline M.C. $5,0 \%$ & 3,51 & 3,70 & 3,54 & 3,42 & 3,7 & 3,35 & 3,74 & 3,35 & 3,65 & 3,71 & 3,60 & 0,15 & 3,38 & 1,55 \\
\hline M.C. $5,5 \%$ & 4,44 & 4,15 & 4,12 & 4,63 & 4,48 & 4,35 & 4,45 & 4,43 & 4,43 & 4,46 & 4,39 & 0,15 & 4,17 & 1,92 \\
\hline M.C. $6,0 \%$ & 4,70 & 5,03 & 5,05 & 5,02 & 5,09 & 5,11 & 5,06 & 5,11 & 5,18 & 5,21 & 5,06 & 0,14 & 4,84 & 2,23 \\
\hline C.M.C. $1,0 \%$ & 0,48 & 0,53 & 0,45 & 0,42 & 0,35 & 0,44 & 0,44 & 0,35 & 0,40 & 0,36 & 0,42 & 0,06 & 0,20 & 0,09 \\
\hline C.M.C. $1,5 \%$ & 0,71 & 0,71 & 0,63 & 0,63 & 0,53 & 0,58 & 0,62 & 0,61 & 0,67 & 0,71 & 0,64 & 0,06 & 0,42 & 0,19 \\
\hline C.M.C. $2,0 \%$ & 1,64 & 1,59 & 1,62 & 1,75 & 1,82 & 1,78 & 1,92 & 1,96 & 1,94 & 1,82 & 1,78 & 0,13 & 1,56 & 0,72 \\
\hline C.M.C. $2,5 \%$ & 2,36 & 2,35 & 2,36 & 2,28 & 2,07 & 2,14 & 2,10 & 2,22 & 2,1 & 2,44 & 2,24 & 0,13 & 2,02 & 0,93 \\
\hline C.M.C. $3,0 \%$ & 4,10 & 3,48 & 3,31 & 3,71 & 4,23 & 3,82 & 3,50 & 3,47 & 3,49 & 3,50 & 3,66 & 0,30 & 3,44 & 1,58 \\
\hline C.M.C. $3,5 \%$ & 4,85 & 4,84 & 4,89 & 4,50 & 4,49 & 4,61 & 4,59 & 4,49 & 4,00 & 3,99 & 4,52 & 0,32 & 4,30 & 1,98 \\
\hline C.M.C. $4,0 \%$ & 5,47 & 5,92 & 6,23 & 5,47 & 6,17 & 5,98 & 6,43 & 7,22 & 6,44 & 7,21 & 6,25 & 0,61 & 6,03 & 2,77 \\
\hline C.M.C. $4,5 \%$ & 8,23 & 7,57 & 8,64 & 8,80 & 8,23 & 7,55 & 7,61 & 7,67 & 7,52 & 7,60 & 7,84 & 0,49 & 7,62 & 3,50 \\
\hline C.M.C. $5,0 \%$ & 10,16 & 9,77 & 11,02 & 9,77 & 10,54 & 9,78 & 11,14 & 9,78 & 8,31 & 8,53 & 9,88 & 0,93 & 9,66 & 4,44 \\
\hline C.M.C. $5,5 \%$ & 12,42 & 12,22 & 12,53 & 13,33 & 12,42 & 12,22 & 14,65 & 12,37 & 12,42 & 12,38 & 12,67 & 0,76 & 12,45 & 5,73 \\
\hline C.M.C. $6,0 \%$ & 14,65 & 15,59 & 13,54 & 12,25 & 14,51 & 14,76 & 13,35 & 13,73 & 12,97 & 14,50 & 13,98 & 0,99 & 13,46 & 6,19 \\
\hline Viscoat & 0,67 & 0,77 & 0,72 & 0,71 & 0,73 & 0,70 & 0,69 & 0,77 & 0,84 & 0,87 & 0,75 & 0,07 & 0,53 & 0,24 \\
\hline ProVisc & 1,45 & 1,28 & 1,32 & 1,39 & 1,46 & 1,30 & 1,40 & 1,38 & 1,47 & 1,49 & 1,39 & 0,08 & 1,17 & 0,54 \\
\hline
\end{tabular}

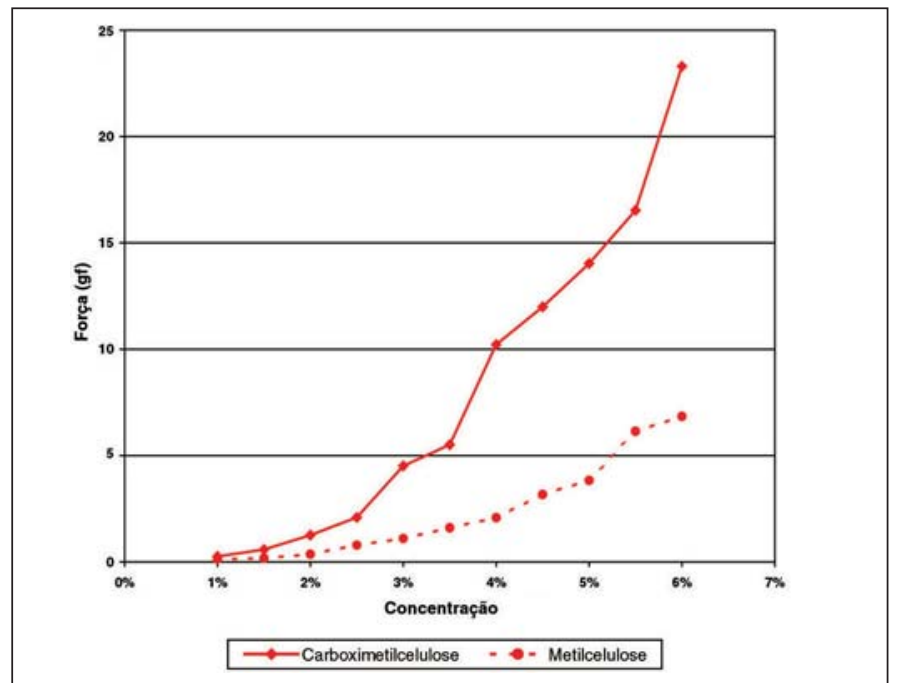

Gráfico 1 - Relação entre concentração de metilcelulose e carboximetilcelulose e força obtida (descontada a média do atrito interno e corrigida para o momento de aplicação) no estudo da ÁREA 1

A substância ideal para o propósito deste estudo deverá apresentar, como resultado, valores superiores aos das forças promovedoras de instabilidade e, ao mesmo tempo, inferiores aos das forças envolvidas nas rotações oculares. Além disso, seria importante que tais valores fossem obtidos na menor área de contato, pois isso diminuiria as dificuldades para a aplicação "in vivo".

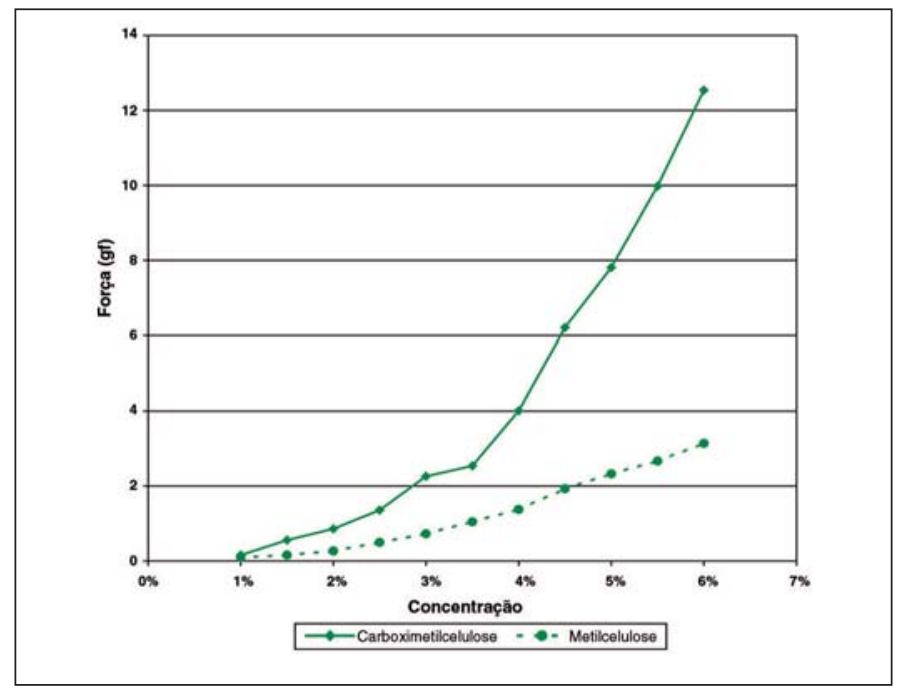

Gráfico 2 - Relação entre concentração de metilcelulose e carboximetilcelulose e força obtida (descontada a média do atrito interno e corrigida para o momento de aplicação) no estudo da ÁREA 2

O olho não é perfeitamente esférico, sua massa (cerca de $7 \mathrm{~g}$ ) não está uniformemente distribuída, de modo que seu centro de massa não coincide com seu centro geométrico. $\mathrm{O}$ próprio centro de rotação não é fixo, sofrendo pequenos deslocamentos translacionais durante as contrações musculares. Contudo, é tradicional nos estudos da mecânica ocular considerar algumas idealizações que proporcionam simplificações 


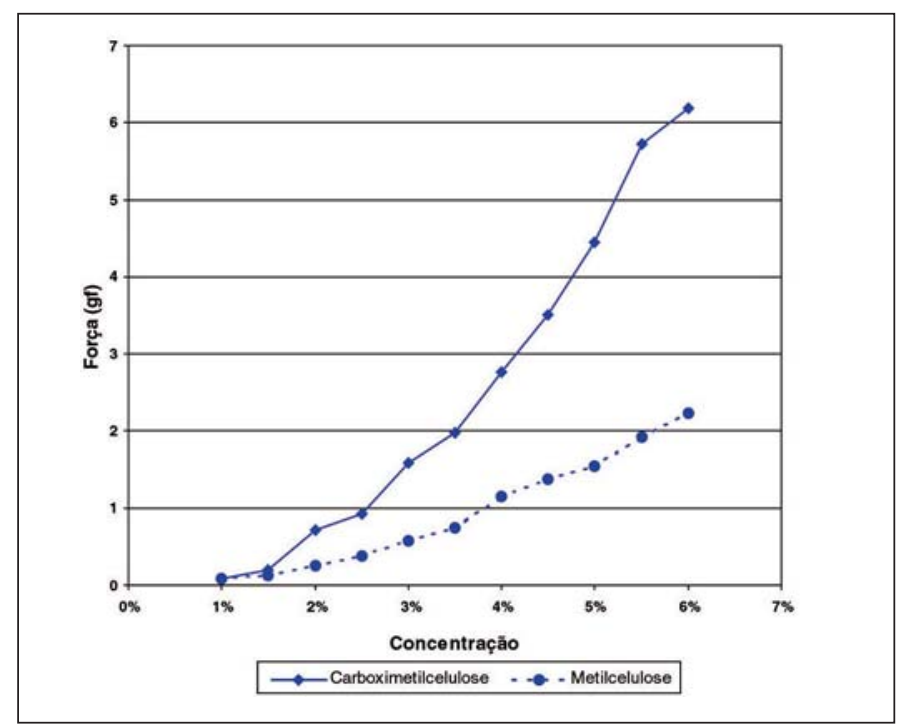

Gráfico 3 - Relação entre concentração de metilcelulose e carboximetilcelulose e força obtida (descontada a média do atrito interno e corrigida para o momento de aplicação) no estudo da ÁREA 3

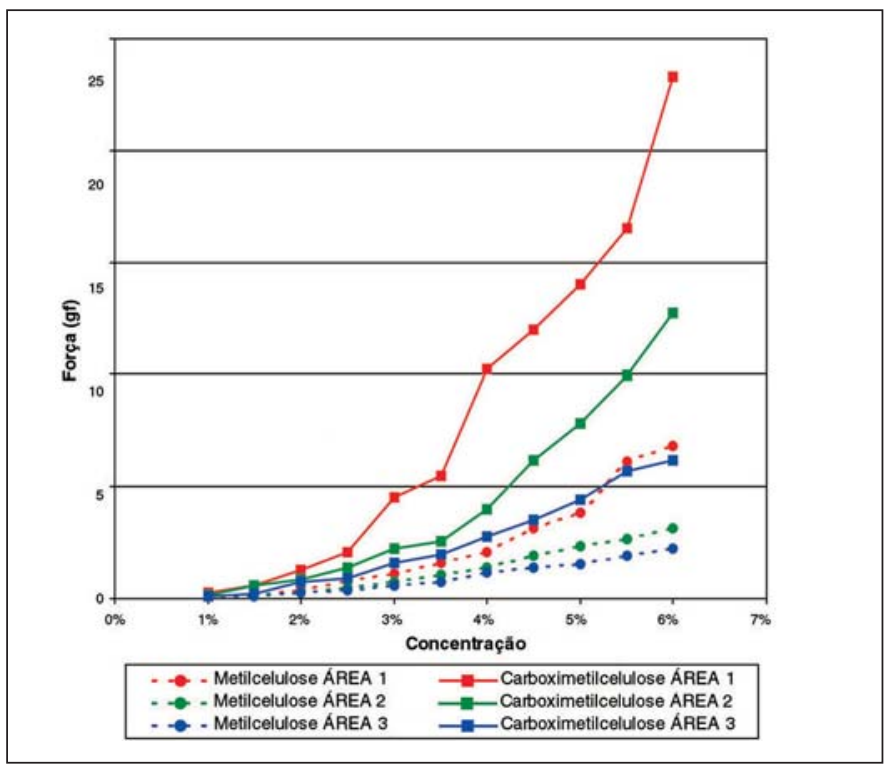

Gráfico 4 - Relação entre concentração de metilcelulose e carboximetilcelulose e força obtida (descontada a média do atrito interno e corrigida para o momento de aplicação) nas diferentes áreas estudadas

de análises. Deste modo o olho é considerado como uma esfera homogênea, sendo aceita a coincidência dos centros de massa, de rotação e geométrico ${ }^{(8)}$. Para o modelo utilizado neste estudo deve-se admitir tais aproximações, porém é necessário também lembrar que a consistência e também o relevo (e, portanto, o atrito) do alumínio são diferentes dos tecidos do bulbo ocular, ainda mais considerando-se as estruturas que o envolvem (músculos, ligamentos, vasos, etc). Pode-se, assim, supor que o atrito "in vivo" seja algo maior que o do modelo mecânico que apresentou uma superfície bastante lisa, livre de alterações de relevo, o que não ocorre no olho.

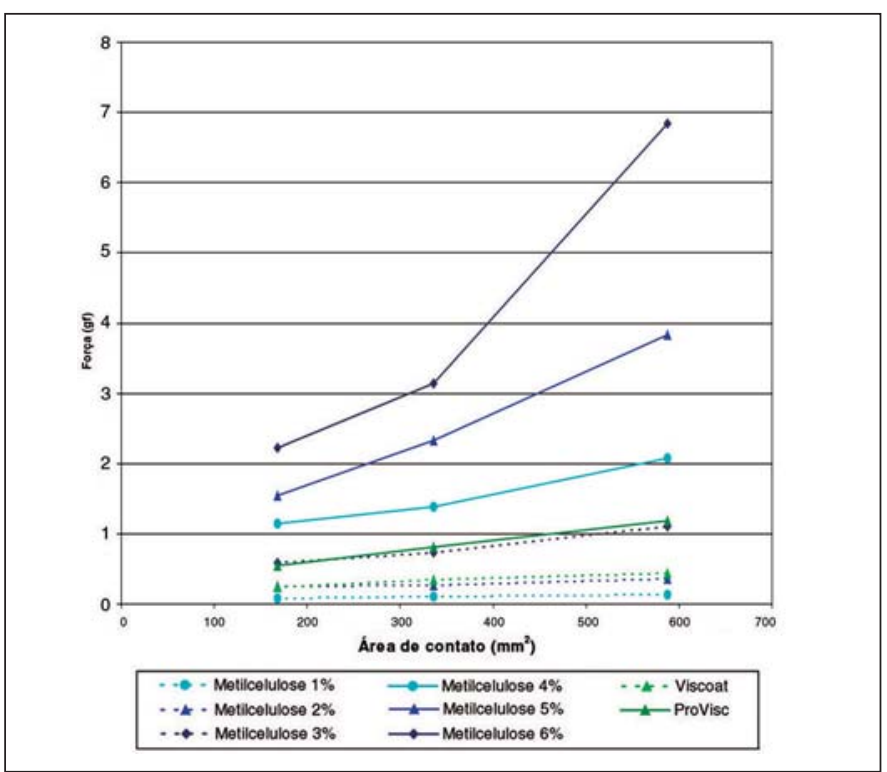

Gráfico 5 - Relação entre área de contato e força obtida (descontada a média do atrito interno e corrigida para o momento de aplicação) para algumas das soluções viscosas (metilcelulose a $1 \%, 2 \%$ e $3 \%, 4 \%$,

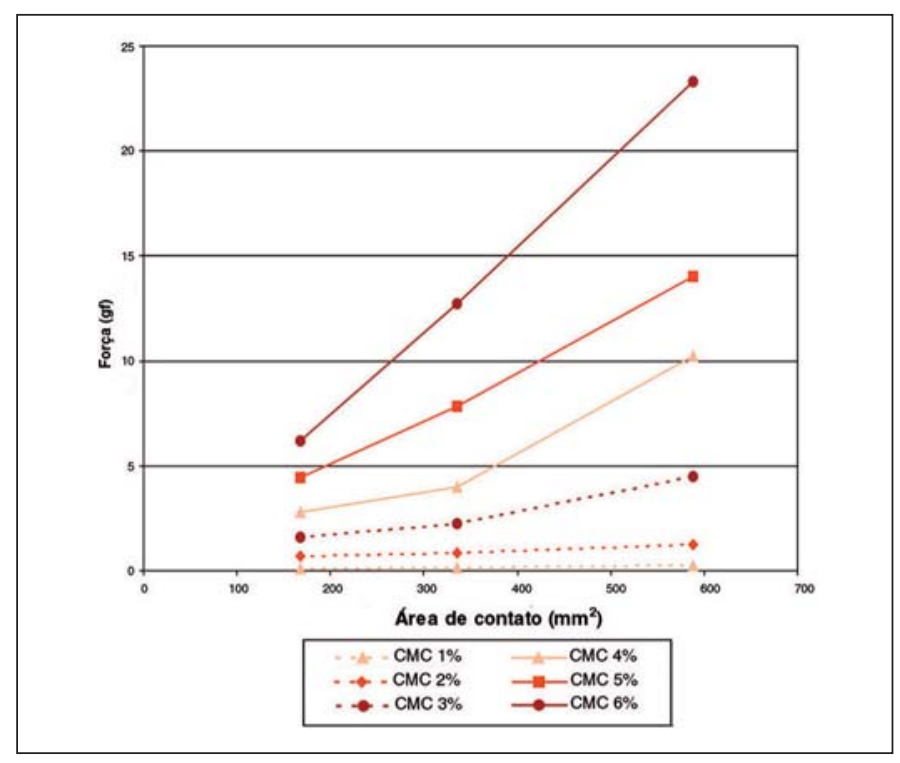

Gráfico 6 - Relação entre área de contato e força obtida (descontada a média do atrito interno e corrigida para o momento de aplicação) para algumas das soluções viscosas (carboximetilcelulose a $1 \%, 2 \%, 3 \%$, $4 \%, 5 \%$ e $6 \%$ )

A análise geral dos resultados mostra que, nas três áreas estudadas, houve um incremento progressivo da força média necessária para mover a esfera, em consequiência do aumento da concentração de metilcelulose e carboximetilcelulose, como se pode observar nos gráficos 1 a 4 .

Os gráficos 5 e 6 mostram que houve incremento da força média de acordo com o aumento da área de contato. Tal comportamento foi observado em todas as soluções de metilcelulose e carboximetilcelulose, assim como nos dois viscoelásti- 
cos estudados. O gráfico 5 também mostra que, em relação aos viscoelásticos, o comportamento do Viscoat ${ }^{\circledR}$ foi semelhante ao da solução de metilcelulose na concentração de 2,0\%, ao passo que o comportamento do Provisc ${ }^{\circledR}$ aproximou-se ao da solução de metilcelulose na concentração de 3,0\%.

Considerando a relação $\mathrm{F}_{\mathrm{i}}<\mathrm{F}<\mathrm{F}_{\mathrm{n}}$ (apresentada na introdução), estando $F_{i}$ (para os nistagmos) entre 5 e 10 gf e $F_{n}$ entre 65 e $100 \mathrm{gf}$ (forças envolvidas em rotações oculares entre $15^{\circ} \mathrm{e}$ $30^{\circ}$ ), nota-se que, em relação à metilcelulose somente as soluções a 5,5\% e 6,0\% na ÁREA 1 poderiam cumprir a primeira condição $\left(F_{i}<F\right)$. Nas outras duas áreas de contato nenhuma das soluções de metilcelulose alcançou valores para cumprir tal condição. Nenhum dos dois viscoelásticos alcançou valores necessários para cumprir a condição $\mathrm{F}_{\mathrm{i}}<\mathrm{F}$ em nenhuma das três áreas de contato estudadas. Os resultados com a carboximetilcelulose foram mais promissores. A condição $F_{i}<F$ foi cumprida nas concentrações de 3,5\%, 4,0\%, 4,5\%, 5,0\%, 5,5\% e 6,0\% na ÁREA 1, nas concentrações de 4,5\%, 5,0\%, 5,5\% e $6,0 \%$ na ÁREA 2, e nas concentrações de 5,5\% e 6,0\% na ÁREA 3. Todas as soluções de metilcelulose e carboximetilcelulose e os dois viscoelásticos, nas três áreas estudadas, cumpriram a segunda condição $\left(F<F_{n}\right)$ e, sendo assim, não limitariam as rotações obtidas por contrações musculares (forças ativas).

Portanto, a análise isolada dos resultados obtidos para cada área de contato leva a crer que as soluções de metilcelulose a $5,5 \%$ e $6,0 \%$ e carboximetilcelulose de $3,5 \%$ a $6,0 \%$ na ÁREA 1, carboximetilcelulose de $4,5 \%$ a $6,0 \%$ na ÁREA 2, e carboximetilcelulose a 5,5\% e 6,0\% na ÁREA 3 atingiriam valores teoricamente suficientes (acima de $5 \mathrm{gf}$ ) para conter, ao menos, alguns tipos de nistagmos. Entretanto, deve-se considerar que, sendo a área total da esfera de $2242,3 \mathrm{~mm}^{2}$ $\left(4 \pi R^{2}\right)$, a ÁREA 1 corresponde a 26,21\% daquela área e, sob o ponto de vista de aplicabilidade in vivo, seria bastante improvável conseguir-se uma área de contato dessa dimensão (envolvendo cerca de $1 / 4$ do bulbo ocular). Sob esse aspecto, a ÁREA 2, com 14,98\%, e, principalmente, a ÁREA 3, que abrange 7,49\% da área total, estariam mais próximas da viabilidade clínica. Assim, a carboximetilcelulose nas concentrações a partir de 4,5\% e, principalmente, a 5,5\% e 6,0\% parece ser boa opção para os objetivos do presente estudo.

Sugere-se que novos estudos busquem a viabilização in vivo de um sistema dessa natureza. Acredita-se que tal viabilização seja difícil, porém viável.

\section{CONCLUSÃO}

Os resultados deste estudo permitem concluir em um modelo mecânico, que a aplicação de carboximetilcelulose em concentração de 5,5\% e 6\% sobre uma área de 7,49\% da área total de uma esfera de alumínio de $26,73 \mathrm{~mm}$ de diâmetro é capaz de gerar uma força de atrito frenadora acima de $5 \mathrm{gf}$. Esta força é supostamente capaz de frenar os movimentos dos nistagmos sem impedir as rotações oculares.

\section{ABSTRACT}

Purpose: From a quantitative point of view, to determine if the viscous friction forces could act as possible promoters of ocular stabilization keeping the rotational movements, which would provide the necessary values to be used in the ocular system. Methods: A mechanical model was created to measure the necessary forces to overcome the friction of an alluminum sphere partially kept in a viscous liquid. Solutions of carboxymethylcellulose from $1.0 \%$ to $6.0 \%$ (with a variation of $0.5 \%$ ) were used. Another variant to be considered was the area of contact between the sphere and the viscous liquid. Results: After appropriate corrections and discounts a meaningful force (over $5 \mathrm{gf}$ ) was found in the solutions of carboxymethylcellulose at $3.5 \%$ or more in the largest contact area $\left(587.8 \mathrm{~mm}^{2}\right)$, in the solutions of carboxymethylcellulose at $4.5 \%$ or more in the intermediate area $\left(335.9 \mathrm{~mm}^{2}\right)$, in the solutions of carboxymethylcellulose at $5.5 \%$ and $6.0 \%$ in the smallest area $\left(167.9 \mathrm{~mm}^{2}\right)$. Conclusion: Some of the viscous liquids tested are apparently able to ensure enough friction force for ocular stabilization, specially the solutions of carboxymethylcellulose at $5.5 \%$ and $6.0 \%$ which provided good results in the smallest contact area.

Keywords: Oculomotor muscles; Eye movements; Nystagmus, pathologic; Strabismus; Viscosity; Carboxymethylcellulose; Optical rotation

\section{REFERÊNCIAS}

1. Bicas HEA. Ajustamentos posicionais oculares e estabilizações do equilíbrio oculomotor sem impedir rotações. Arq Bras Oftalmol. 1998;61(3):294-304.

2. Bicas HEA. Geração de rotações binoculares combinadas em casos de perdas de ação muscular: mecanismos para conjugações rotacionais. Arq Bras Oftalmol. 1996;59(2):119-28.

3. Jorge AAH. Viscosidade como fator frenador de rotações. Arq Bras Oftalmol. 2003;66(4):465-72.

4. Bicas HEA. Princípios teóricos de substituição de ação rotacional de músculo extra-ocular. IV Relações quantitativas entre forças aplicadas e rotações obtidas. Arq Bras Oftalmol. 1984;47(6):195-200.

5. Scott AB, Collins CC, O'Meara DM. A forceps to measure strabismus forces. Arch Ophthalmol. 1972;88(3):330-3.

6. Faires VM. Elementos orgânicos de máquinas II. Rio de Janeiro: LTC; 1975.

7. Purquério BM. Tribologia VIII - Mancais aerostáticos (ábacos) [apostila]. São Carlos, Escola e Engenharia de São Carlos - USP: Serviço Gráfico; 1990.

8. Bicas HEA. Fundamentos e considerações preliminares na geração de rotações binoculares combinadas em casos de perda de ação muscular. Rev Bras Oftalmol. 1996;55(6):31-43. 